\title{
Variability of Transition Rate and Gender Parity in Rural Primary School Level in Gopiballavpur Circle (West), Paschim Medinipur, West Bengal: A Case Specific Study
}

\author{
Mrityunjoy Jana', Ansar Khan², Soumendu Chatterjee ${ }^{3}$, Nityananda Sar', Arosikha Das ${ }^{5}$ \\ ${ }^{1}$ Department of Education, Vinayaka Missions University, Salem, India \\ ${ }^{2}$ Department of Geography and Environment Management, Vidyasagar University, Midnapore, India \\ ${ }^{3}$ Department of Geography, Presidency University, Kolkata, India \\ ${ }^{4}$ Department of Geography, Kharagpur College, Kharagpur, India \\ ${ }^{5}$ Department of Applied Geography, Ravenshaw University, Cuttack, India \\ Email: janamritedu@gmail.com, khanansargeo@gmail.com, scgeovu@yahoo.co.in, sarnityananda@gmail.com, \\ dasarogeoru@gmail.com
}

Received 7 October 2014; revised 5 November 2014; accepted 27 November 2014

Copyright (C) 2014 by authors and Scientific Research Publishing Inc.

This work is licensed under the Creative Commons Attribution International License (CC BY).

http://creativecommons.org/licenses/by/4.0/

(c) (i) Open Access

\section{Abstract}

This paper assesses variability of transition rate and gender parity in rural primary school level in Gopiballavpur Circle (West), Paschim Medinipur, West Bengal. With respect to 2003-2012 (ten academic sessions) registered enrolment record in two primary schools, the variability of transition rates was calculated for each school using actual values of measurable parameters relating to study. Thus, a transition rates was assigned to each of the schools according to the degree of transition rates. Similarly, gender parity for each school was derived from male and female registered pupils. The ratio of female and male was used to calculate the gender parity for the schools, which was then multiplied by the percent of value occurrences to obtain the gender parity index (GPI). This analysis was used to divide the transition rate into four assigned threshold including on the basis of positive and negative numeric a) very low transition rate $(0 \%-25 \%)$; b) medium transition rate (26\% - 50\%); c) high transition rate (51\% - 75\%); and d) very high transition rate $(76 \%$ $100 \%)$. Whereas, gender parity divided into three assigned attributes (a) gender parity index $(=1)$ for parity between females and males pupils; (b) gender parity index $(<1)$ disparity in favour of male pupils; and (c) gender parity index (>1) disparity in favour of female pupils. However, the interpretation should be the other way rounded for indicators that should ideally approach tends 
to be $0 \%$ (e.g. repetition, dropout, illiteracy rates, etc.). Overall, this type of transition rates and gender parity assessment may prove useful for future school planning and management programs in rural primary school.

\title{
Keywords
}

\author{
Transition Rates, Gender Parity, Rural Primary School, Academic Year
}

\section{Introduction}

This literature focuses on several key issues at the heart of the current debate over the quality of elementary education system (Alspaugh, 1998a; Anderson et al., 2000). Trends in elementary education system achievement and course taking are examined first, both as system outputs and as the context for current reform efforts by transition rate and gender parity. Maintaining the elementary education system pipeline and preparing all young people for an increasingly technological society are two goals driving reforms targeted to raise the academic bar for students and improve the quality of teaching in a particular society (Alspaugh, 1998d; Anderson et al., 2000). The desire to raise the academic expectations for all students has led states to both adopt standards specifying what students should know and be able to do and to implement new testing mechanisms to measure what students actually know.

Although it is widely recognized that education reforms cannot be successful without actively engaging teachers, comprehensive, valid measures of change in teacher quality are difficult to come by, leaving us to rely on currently available data. Indicators of teacher credentials, experience, and participation in professional development activities are presented, as well as data on how new teachers are being inducted into the professional signature on flow transition and in parity or disparity in favour of males pupils as well as females ones (Blyth et al., 1983; Breen \& Buchman, 2002). This several study emphasizes variation in both access to education resources (by school poverty level and minority concentration) and performance (by sex, race/ethnicity, and family background) as data availability allows. A distinction is also made between mathematics and science when the policy implications of data are different or the data tell different stories (Breen \& Buchman, 2002; Bruner, 1996).

Free and compulsory education to all children up to the age of fourteen years is our Constitutional commitment. The Government of India has initiated a number of programmes to achieve the goal of universalization of Elementary Education (UEE) among which the Sarva Shiksha Abhiyan (SSA) is the most recent one. It aims at achieving universal primary education by 2007 and universal elementary education by 2010. Achieving universalization means achieving universal access, universal enrolment, universal retention and universal quality of education. Though indicators to monitor progress towards universal access, enrolment and quality are well defined but the general perception about same is not clear in case of indicators of universal retention. In simple terms, universal retention at primary level means every child enter into the system through Class I should retain in the system up to Class IV (Campbell, 2001). Universal retention under SSA by 2007 means that all children enrolled in Class I in 2002-03 should retain in the system and move up to Class IV in 2007. Depending upon the availability of data and understanding of concept of transition rate, indicators of gender parity are computed and analysed.

Keeping in view availability of data, an attempt has been made in the present note to assess computation procedure of a variety of transition rate and gender parity. Since recent class-specific enrolment and repeaters data are available school registered book and from District Information System for Education (DISE), the same is used to construct indicators of gender parity.

In view of availability of enrolment and repeaters data, a particular method for assessing drop-out and retention is applied. However, it is the transition rate which presents true picture of retaining capacity of the system. A number of states have initiated child-tracking studies across the country but in view of resource and time constraints the same is not an easy task to undertake gender parity annually. Each and every enrolled child in a school is tracked/monitored over a period of five years or till a child remains in the system. The research studies undertaken in the recent past tracked child for five years to measure gender parity, completion rate; thus presents percentage of children those who completed primary level exactly in five years (Campbell, 2001; Dubois et al., 
1994). This presents incomplete completion rate as a number of children still remain in the system even after five years because of repetition. The system should be monitored till the last child remains in the system (Dubois et al., 1994). If resources are available, child-tracking is the only way through which gender parity, drop-out, retention, survival and completion rates should be analysed. School registers for five years are used to track a group of children those who enter into the system together. A few states have designed their own formats and even developed software for the purpose. If tracked for different cohorts and separately for male and female, the same can help in monitoring progress towards retaining capacity of the system as well as assessing completion rate.

Depending upon availability of data, an indicator to measure drop-out rate should be developed (Bruner, 1996; Campbell, 2001). If resources available, true-cohort study where each and every enrolled child is tracked should be undertaken which can be used for both assessing drop-out as well as completion rate. If resources are not available and data available, retention rate by using enrolment and repeaters data over a period of five years should only be utilized to assess retaining capacity of an education system. The transition rate so obtained is subtracted from 100 to obtain drop-out rate at an educational level (Alspaugh \& Harting, 1995). To know real cause of low retention/high transition rate, it is essential that the same be calculated and analysed at disaggregated levels and if data available, separately for male and female, rural and urban areas and for schedule caste (SC) and schedule tribe (ST) children (Alspaugh, 1998b).

The root cause of high transition rate can be identified by calculating class-to-class flow rates such as, promotion, drop-out and repetition rate (Alspaugh, 1998c; Bryk \& Thum, 1989). This will help a district/state in identifying in which class there is high incidence of drop-out and repetition and also in knowing whether the same is because of male/female SC/ST children. The class-to-class drop-out rates can also be used in assessing average transition rate and repetition during intermediary year. The average indicate quantum of transition rate as well as gender parity during intermediary year in relation to total enrolment in primary classes (Frymier, 1996; Gardner et al., 2000). Average transition rate can also be used to examine trends in transition rate and gender parity over a period of time but the same is different than the retention rate which is based upon enrolment data over a period of five years where as average transition rate is simply based upon enrolment and repeaters data of only two years. As has been demonstrated in this note, class-to-class transition rates can also be used to do construct indicators of internal efficiency of education system (Kaplan et al., 1996; Lee \& Smith, 1997; Phelan, 1992).

By just quantifying transition rate, the situation will not improve automatically for that purpose the first major exercise is to know reasons of low promotion and high transition rate and repetition (Rumberger, 1987; Dev, 1995). This should necessarily follow by reason and area specific strategies without which no improvement is expected. This should form part of Annual Work Plan and Budget under Sarva Shiksha Abhiyan SSA and the Project Approval Board should rigorously monitor it. Year 2010 is approaching fast and we cannot sit hoping that situation (with regard to transition rate and gender parity) will improve automatically. Still we have more four years to more optimally and rigorously utilize provisions made under SSA to work towards achieving universal elementary education in transition rate and gender parity (Vaidyanathan \& Nair, 2001).

\section{Materials and Methods}

\subsection{Materials}

The total sample size decided to be covered under the study was two schools. The simple circular systematic procedure was used which implicitly maintained the same proportion in the subsample as that of in the sampling frame. For selection of 'Schools with lower primary classes only' within Gopiballavpur Circle (West), Paschim Medinipur, the list of all such schools was first arranged in ascending order on the basis of total enrolment (Classes I-IV). In case the total enrolment in a school was less than 10, it was excluded. With the help of this list, two schools (which are fells into more inaccessible and backward area than other schools within circle) were selected by circular systematic sampling method (Aikara, 1997). However, Researchers have used enrolment records collected from daily attendance book, considered for study from both school. The considered data period ranges from 2003 to 2013 (ten academic sessions) and the data are continuous without any missing data. Those data were organized and then reduced to class wise for further study shown in Table 1. Statistically processed by student $t$ test $p<0$, the critical value of $t$ at 0.05 significance level with 8 degree of freedom is 2.31 . Thus, as $t_{0.05}<2.61$ and $t_{0.05}<2.51$ the value of correlation coefficient (r) are significant in Table 2. 
Table 1. School wise student enrolments at base year class (i.e. first academic session 2003-04).

\begin{tabular}{|c|c|c|c|c|c|c|c|c|c|c|}
\hline \multirow{2}{*}{ School } & \multirow{2}{*}{ Academic Year } & \multicolumn{2}{|c|}{ Class-I } & \multicolumn{2}{|c|}{ Class-II } & \multicolumn{2}{|c|}{ Class-III } & \multicolumn{2}{|c|}{ Class-IV } & \multirow{2}{*}{ Total } \\
\hline & & Male & Female & Male & Female & Male & Female & Male & Female & \\
\hline \multirow{10}{*}{ MSPS } & 2003-04 & 12 & 25 & 10 & 11 & 6 & 5 & 9 & 3 & 81 \\
\hline & 2004-05 & 15 & 14 & 12 & 25 & 9 & 11 & 6 & 5 & 97 \\
\hline & 2005-06 & 15 & 19 & 15 & 14 & 12 & 24 & 9 & 11 & 119 \\
\hline & 2006-07 & 7 & 5 & 15 & 18 & 15 & 13 & 11 & 23 & 107 \\
\hline & 2007-08 & 11 & 13 & 7 & 5 & 13 & 17 & 14 & 13 & 93 \\
\hline & 2008-09 & 16 & 14 & 11 & 12 & 7 & 5 & 13 & 17 & 95 \\
\hline & $2009-10$ & 20 & 17 & 16 & 13 & 11 & 12 & 7 & 5 & 101 \\
\hline & 2010-11 & 11 & 13 & 19 & 16 & 15 & 13 & 11 & 12 & 110 \\
\hline & 2011-12 & 9 & 7 & 11 & 13 & 19 & 16 & 14 & 12 & 101 \\
\hline & 2012-13 & 17 & 11 & 9 & 7 & 11 & 12 & 18 & 15 & 100 \\
\hline \multirow{10}{*}{ BPS } & 2003-04 & 5 & 2 & 7 & 9 & 5 & 8 & 10 & 6 & 52 \\
\hline & 2004-05 & 9 & 3 & 5 & 2 & 7 & 8 & 5 & 8 & 47 \\
\hline & 2005-06 & 7 & 8 & 9 & 2 & 5 & 2 & 7 & 8 & 48 \\
\hline & 2006-07 & 6 & 3 & 7 & 8 & 9 & 2 & 4 & 2 & 41 \\
\hline & 2007-08 & 9 & 14 & 6 & 3 & 7 & 8 & 9 & 2 & 58 \\
\hline & 2008-09 & 13 & 9 & 8 & 13 & 6 & 3 & 7 & 7 & 66 \\
\hline & 2009-10 & 6 & 9 & 13 & 9 & 8 & 12 & 6 & 3 & 66 \\
\hline & 2010-11 & 11 & 9 & 6 & 9 & 10 & 8 & 8 & 12 & 73 \\
\hline & 2011-12 & 10 & 8 & 10 & 9 & 6 & 9 & 10 & 8 & 70 \\
\hline & 2012-13 & 7 & 12 & 9 & 8 & 10 & 9 & 6 & 8 & 69 \\
\hline
\end{tabular}

Table 2. Statistically processed data reduced to class wise testing for significance between male and female.

\begin{tabular}{|c|c|c|c|c|c|}
\hline \multirow{2}{*}{ School } & \multirow{2}{*}{ Class } & \multicolumn{2}{|l|}{ Male } & \multicolumn{2}{|l|}{ Female } \\
\hline & & Correlation Coefficient (r) & $t$ Value & Correlation Coefficient (r) & $t$ Value \\
\hline \multirow{4}{*}{ MSPS } & Class-I & 0.14 & 0.40 & 0.53 & 1.81 \\
\hline & Class-II & 0.10 & 0.28 & 0.38 & 1.19 \\
\hline & Class-III & 0.52 & 1.72 & 0.10 & 0.28 \\
\hline & Class-IV & $0.68^{*}$ & 2.61 & 0.33 & 0.99 \\
\hline \multirow{4}{*}{ BPS } & Class-I & 0.36 & 1.09 & $0.66^{*}$ & 2.51 \\
\hline & Class-II & 0.45 & 1.41 & 0.43 & 1.37 \\
\hline & Class-III & 0.56 & 1.94 & 0.39 & 1.19 \\
\hline & Class-IV & 0.10 & 0.28 & 0.26 & 0.78 \\
\hline
\end{tabular}

${ }^{*}$ For $\mathrm{H}_{1}: p<0$, the critical value of $t$ at 0.05 significance level with 8 degree of freedom is 2.31 . Thus, as $t_{0.05}<2.61$ and $t_{0.05}<2.51$ the value of correlation coefficient (r) are significant.

\subsection{Methods}

\subsubsection{Transition Rate (TR)}

The number of pupils (or students) admitted to the first class of a higher level of education in a given year, expressed as a percentage of the number of pupils (or students) enrolled in the final class of the lower level of 
education in the previous year. To convey information on the degree of access or transition from one cycle or level of education to higher levels (Bajpai, 2003). Viewed from the lower cycle or level of education, it is considered as an output indicator, viewed from the higher educational cycle or level, it constitutes an indicator of access. It can also help in assessing the relative selectivity of an education system, which can be due to pedagogical or financial requirements. Divide the number of new entrants in the first class of the specified higher cycle or level of education by the number of pupils who were enrolled in the final class of the preceding cycle or level of education in the previous school year, and multiply by 100 .

$$
T R_{h, h+1}^{t}=\frac{E_{h+1,1}^{t+1}-R_{h+1,1}^{t+1}}{E_{h, n}^{t}} \times 100
$$

where,

$T R_{h, h+1}^{t}=$ Transition rate (from cycle or level of education $h$ to $h+1$ in school year $t$ );

$E_{h+1,1}^{t+1}=$ Number of pupils enrolled in the first class at level of education $h+1$ in school year $t+1$;

$R_{h+1,1}^{t+1}=$ Number of pupils repeating the first class at level of education $h+1$ in school year $t+1$;

$E_{h, n}^{t}=$ Number of pupils enrolled in final class $n$ at level of education $\mathrm{h}$ in school year $t$.

High transition rates indicate a high level of access or transition from one level of education to the next (Clayton, 2006). They also reflect the intake capacity of the next level of education. Inversely, low transition rates can signal problems in the bridging between two cycles or levels of education, due to either deficiencies in the examination system, or inadequate admission capacity in the higher cycle or level of education, or both. This indicator can be distorted by incorrect distinction between new entrants and repeaters, especially in the first class of the specified higher level of education. Students who interrupted their studies for one or more years after having completed the lower level of education, together with the migrant students, could also affect the quality of this indicator.

\subsubsection{Gender Parity Index (GPI)}

Gender parity (GPI) ratio of female to male values of a given indicator is generally known as gender parity index (Dreze \& Sen, 2002; Lathika \& Kumar, 2008). The GPI measures progress towards gender parity in education participation and/or learning opportunities available for women in relation to those available to men. It also reflects the level of women's empowerment in society. Divide the female value of a given indicator by that of the male.

$$
G P I_{i}^{t}=\frac{F_{i}^{t}}{M_{i}^{t}}
$$

where,

$G P I_{i}^{t}=$ Gender parity index of a given indicator $i$ in year $t$;

$F_{i}^{t}=$ Female value of a given indicator $i$ in year $t$;

$M_{i}^{t}=$ Male value of the same indicator $i$ in year $t$.

A GPI equal to 1 indicates parity between females and males. In general, a value less than 1 indicates disparity in favour of male and a value greater than 1 indicates disparity in favour of female. However, the interpretation should be the other way round for indicators that should ideally approach $0 \%$ (e.g. repetition, dropout, illiteracy rates, etc.). In these cases, a GPI of less than 1 indicates a disparity in favour of female and a value greater than 1 indicates a disparity in favour of male. The index does not show whether improvement or regression is due to the performance of one of the gender groups. Interpretation requires trend analysis of the underlying indicators (World Bank, 2003; Subrahmanian, 2003b).

\section{Results and Discussion}

In this study, authors investigated how transition rates and gender parity vary between two backward rural primary schools in Gopiballavpur Circle (West), Paschim Medinipur, West Bengal. All of two schools in this study were classified into intermediate classes to a very transition rates and gender parity. With respect to 2003-2013 (ten academic sessions) registered enrolment record in two primary schools, the variability of transition rates 
was calculated for each school using actual values of measurable parameters relating to study. Thus, a transition rates was assigned to each of the schools according to the degree of transition rates. Similarly, gender parity for each school was derived from male and female registered pupils. The ratio of female and male was used to calculate the gender parity for the schools, which was then multiplied by the percent of value occurrences to obtain the gender parity index (GPI).

This analysis was used to divide the transition rate into four assigned threshold including on the basis of positive and negative numeric 1 ) very low transition rate $(0 \%-25 \%) ; 2)$ medium transition rate $(26 \%-50 \%)$; 3 ) high transition rate (51\% - 75\%); 4) very high transition rate ( $76 \%$ - 100\%). Whereas, gender parity divided into three assigned attributes a) gender parity index $(=1)$ for parity between females and males pupils; b) gender parity index $(<1)$ disparity in favor of male pupils; and c) gender parity index $(<1)$ disparity in favor of female pupils. However, the interpretation should be the other way round for indicators that should ideally approach $0 \%$ (e.g. repetition, dropout, illiteracy rates, etc. Overall, this type of transition rates and gender parity assessment may prove useful for future school planning and management programs in rural primary school (Ramachandran, 2004a; Jain \& Arora, 1995).

\subsection{Transition Rate (TR)}

One of the important indicators on which the expansion of upper primary education depends is transition rate from primary to upper primary level of education (Ministry of Human Resource Development, 1992). The transition rate presented in Table 3 and Figure 1 shows total enrolment in each class i.e. Class I to Class IV and

Table 3. Transition rate by total enrolment in each class, i.e. Class I to Class IV.

\begin{tabular}{|c|c|c|c|c|c|c|c|c|c|c|c|c|c|c|c|c|}
\hline & \multirow{2}{*}{ Year } & \multicolumn{3}{|c|}{$\begin{array}{l}\text { Enrolment in } \\
\text { Class-I }\end{array}$} & \multicolumn{3}{|c|}{$\begin{array}{l}\text { Enrolment in } \\
\text { Class-II }\end{array}$} & \multicolumn{3}{|c|}{$\begin{array}{l}\text { Enrolment in } \\
\text { Class-III }\end{array}$} & \multicolumn{3}{|c|}{$\begin{array}{l}\text { Enrolment in } \\
\text { Class-IV }\end{array}$} & \multicolumn{3}{|c|}{ Transition Rate (\%) } \\
\hline & & $\mathbf{M}$ & $\mathbf{F}$ & Total & $\mathbf{M}$ & $\mathbf{F}$ & Total & $\mathbf{M}$ & $\mathbf{F}$ & Total & $\mathbf{M}$ & $\mathbf{F}$ & Total & Class I to II & Class II to III & $\begin{array}{c}\text { Class III } \\
\text { to IV }\end{array}$ \\
\hline \multirow{10}{*}{$\begin{array}{l}\text { M } \\
\text { S } \\
P \\
S\end{array}$} & 2003-04 & 12 & 25 & 37 & 10 & 11 & 21 & 6 & 5 & 11 & 9 & 3 & 12 & 43.24 & 47.61 & -9.09 \\
\hline & 2004-05 & 15 & 14 & 29 & 12 & 25 & 37 & 9 & 11 & 20 & 6 & 5 & 11 & -27.59 & 45.95 & 45 \\
\hline & 2005-06 & 15 & 19 & 34 & 15 & 14 & 29 & 12 & 24 & 36 & 9 & 11 & 20 & 14.71 & -24.14 & 44.44 \\
\hline & 2006-07 & 9 & 9 & 18 & 15 & 18 & 33 & 15 & 13 & 28 & 11 & 23 & 34 & -83.33 & 15.15 & -21.42 \\
\hline & 2007-08 & 11 & 13 & 24 & 7 & 10 & 17 & 13 & 17 & 30 & 14 & 13 & 27 & 29.16 & -76.47 & 10 \\
\hline & 2008-09 & 16 & 14 & 30 & 11 & 12 & 23 & 7 & 9 & 16 & 13 & 17 & 30 & 23.33 & 30.43 & -87.5 \\
\hline & 2009-10 & 20 & 17 & 37 & 16 & 13 & 29 & 11 & 12 & 23 & 7 & 5 & 12 & 21.62 & 20.68 & 47.82 \\
\hline & 2010-11 & 11 & 13 & 24 & 19 & 16 & 35 & 15 & 13 & 28 & 11 & 12 & 23 & -45.83 & 20.00 & 17.85 \\
\hline & 2011-12 & 9 & 7 & 16 & 11 & 13 & 24 & 19 & 16 & 35 & 14 & 12 & 26 & -50 & -45.83 & 25.71 \\
\hline & 2012-13 & 17 & 11 & 28 & 9 & 7 & 16 & 11 & 12 & 23 & 18 & 15 & 33 & 42.85 & -43.75 & -43.47 \\
\hline \multirow{10}{*}{$\begin{array}{l}\mathrm{B} \\
\mathrm{P} \\
\mathrm{S}\end{array}$} & 2003-04 & 5 & 5 & 10 & 7 & 9 & 16 & 5 & 8 & 13 & 10 & 6 & 16 & -60 & 18.75 & -23.07 \\
\hline & 2004-05 & 8 & 4 & 12 & 5 & 7 & 12 & 7 & 8 & 15 & 5 & 8 & 13 & 0 & -25 & 13.33 \\
\hline & 2005-06 & 7 & 8 & 15 & 8 & 3 & 11 & 5 & 6 & 11 & 7 & 8 & 15 & 26.66 & 0.00 & -36.36 \\
\hline & 2006-07 & 5 & 4 & 9 & 7 & 8 & 15 & 9 & 2 & 11 & 4 & 2 & 6 & -66.66 & 26.66 & 45.45 \\
\hline & 2007-08 & 9 & 14 & 23 & 5 & 4 & 9 & 7 & 8 & 15 & 9 & 2 & 11 & 60.86 & -66.66 & 26.66 \\
\hline & 2008-09 & 13 & 9 & 22 & 8 & 13 & 21 & 5 & 4 & 9 & 7 & 7 & 14 & 4.5 & 57.14 & -55.55 \\
\hline & 2009-10 & 7 & 8 & 15 & 13 & 9 & 22 & 8 & 12 & 20 & 6 & 3 & 9 & -46.66 & 9.09 & 55 \\
\hline & 2010-11 & 11 & 9 & 20 & 6 & 9 & 15 & 10 & 8 & 18 & 8 & 12 & 20 & 25 & -20 & -11.11 \\
\hline & 2011-12 & 10 & 8 & 18 & 10 & 9 & 19 & 6 & 9 & 15 & 10 & 8 & 18 & -5.55 & 21.05 & -20.00 \\
\hline & 2012-13 & 7 & 12 & 19 & 9 & 8 & 17 & 10 & 9 & 19 & 6 & 8 & 14 & 10.52 & -11.76 & 26.31 \\
\hline
\end{tabular}

$\mathrm{N}: \mathrm{B}$ M Stands male and F stands female. 


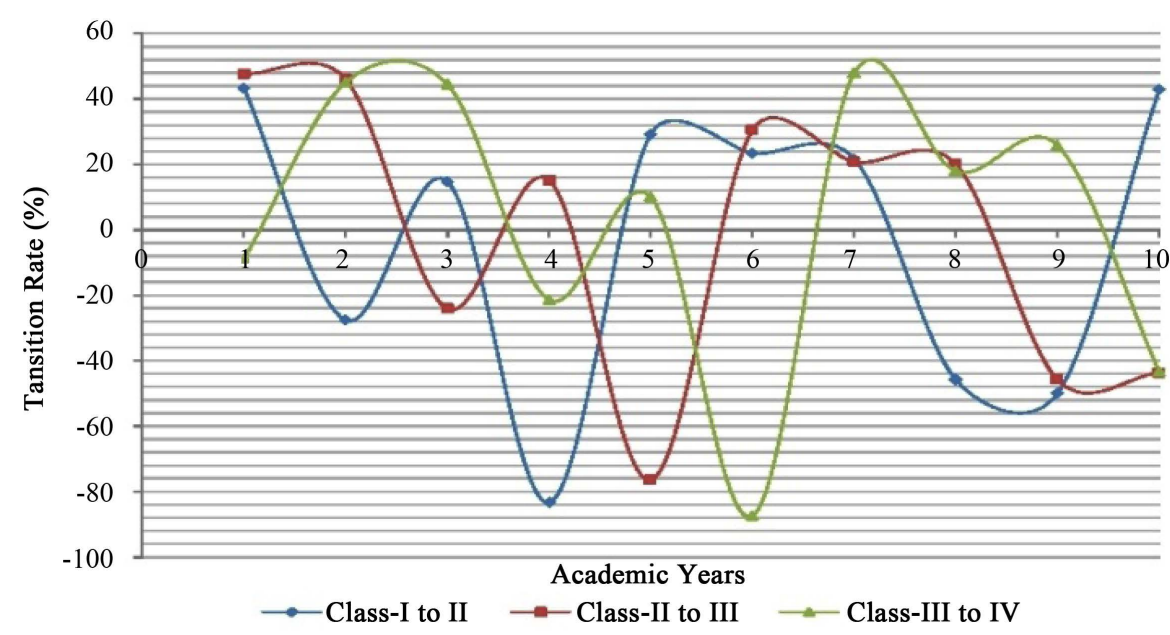

(a)

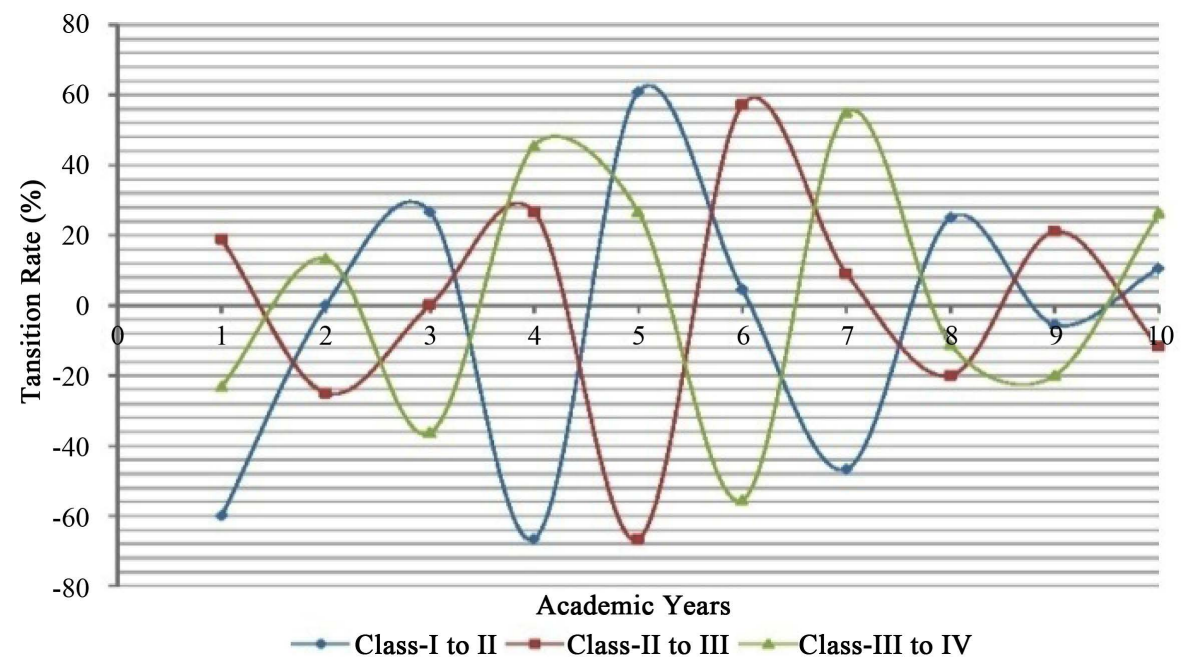

(b)

Figure 1. The transition rate from Class I to Class IV through Class II and Class III for total enrolment for (a) Madansol Primary school and (b) Baital Para Primary school with their academic years.

improvement over the previous year, i.e. 2003-2013 (through ten academic years) based on data of two schools. The average of Madansol Primary School (MSPS) suggests that more than $29.15 \%$ (in case of positive transition) and 51.69\% (in case of negative transition) children in 2003-2013 transited from Class I to Class II primary level of education against $24.24 \%$ and $53.39 \%$ respectively during the previous last ten years. Similarly, up gradation from Class II to Class III reveals the averaged combined together from $2003-13$ is $29.97 \%$ (in case of positive transition) and $47.55 \%$ (in case of negative transition) were found against $26.32 \%$ and $49.29 \%$ respectively during the previous last ten years. In case of final level, i.e. Class III to Class IV provides a vivid scenario between interim periods from 2003-2013 and taken together or taken the academics years averaged by $31.80 \%$ (in case of positive transition) and $40.37 \%$ (in case of negative transition) also tend to found against $27.59 \%$ and $34.79 \%$ respectively during the previous last ten years. But, occurrence of maximum and minimum transition has to be found in 2003-04 for Class II to Class III transition (47.61\%) and $-83.33 \%$ found for Class I to Class II in 2006-07 academic year respectively shown in Table 4.

While, the average of Baital Para Primary school (BPS) suggests that more than 25.51\% (in case of positive transition) and $44.72 \%$ (in case of negative transition) children in 2003-13 transited from Class I to Class II primary level of education against $26.64 \%$ and $51.26 \%$ respectively during the previous last ten years. Similarly, progression from Class II to Class III reveals the averaged combined together from 2003-13 is $26.54 \%$ (in case of 
Table 4. Transition rate from Class I to Class IV through Class II and Class III for total enrolment for two schools with their academic years.

\begin{tabular}{|c|c|c|c|c|c|}
\hline School & $\begin{array}{c}\text { Positive } \\
\text { value (\%) }\end{array}$ & Transition & Class I to II & Class II to III & Class III to IV \\
\hline \multirow{4}{*}{$\begin{array}{c}\mathrm{M} \\
\mathrm{S} \\
\mathrm{P} \\
\mathrm{S}\end{array}$} & $76-100$ & Very high & Nil & Nil & Nil \\
\hline & $51-75$ & High & Nil & Nil & Nil \\
\hline & $26-50$ & Medium & 2003-04, 2007-08, 2012-13 & 2003-04, 2004-05, 2008-09 & $\begin{array}{l}\text { 2004-05, 2005-06, } \\
2009-10,2011-12\end{array}$ \\
\hline & $0-25$ & Low & 2005-06, 2008-09, 2009-10 & 2006-07, 2009-10, 2010-11 & 2007-08, 2010-11 \\
\hline \multirow{4}{*}{$\begin{array}{l}\mathrm{B} \\
\mathrm{P} \\
\mathrm{S}\end{array}$} & $76-100$ & Very high & Nil & Nil & Nil \\
\hline & $51-75$ & High & 2007-08 & 2008-09 & 2009-10 \\
\hline & $26-50$ & Medium & 2005-06 & 2006-07 & $\begin{array}{c}\text { 2006-07, 2007-08, } \\
2012-13\end{array}$ \\
\hline & $0-25$ & Low & $\begin{array}{c}\text { 2004-05, 2008-09, 2010-11, } \\
2012-13\end{array}$ & $\begin{array}{c}\text { 2003-04, 2005-06, 2009-10, } \\
2011-12\end{array}$ & 2004-05 \\
\hline School & $\begin{array}{l}\text { Negative } \\
\text { value (\%) }\end{array}$ & Transition & Class I to II & Class II to III & Class III to IV \\
\hline \multirow{4}{*}{$\begin{array}{c}\mathrm{M} \\
\mathrm{S} \\
\mathrm{P} \\
\mathrm{S}\end{array}$} & -76 to -100 & Very high & 2006-07 & 2007-08 & 2008-09 \\
\hline & -51 to -75 & High & Nil & Nil & Nil \\
\hline & -26 to -50 & Medium & 2011-12 & 2011-12, 2012-13 & 2012-13 \\
\hline & $<-25$ & Low & 2004-05, 2010-11 & 2005-06 & 2003-04, 2006-07 \\
\hline \multirow{4}{*}{$\begin{array}{l}\mathrm{B} \\
\mathrm{P} \\
\mathrm{S}\end{array}$} & -76 to -100 & Very high & Nil & Nil & Nil \\
\hline & -51 to -75 & High & 2003-04, 2006-07 & 2007-08 & 2008-09 \\
\hline & -26 to -50 & Medium & 2009-10 & Nil & 2005-06 \\
\hline & $<-25$ & Low & 2011-12 & 2004-05, 2010-11, 2012-13 & $\begin{array}{c}\text { 2003-04, 2010-11, } \\
2011-12\end{array}$ \\
\hline
\end{tabular}

positive transition) and $-30.86 \%$ (in case of negative transition) were found against $24.29 \%$ and $44.21 \%$ respectively during the previous last ten years. In case of final level, i.e. Class III to Class IV provides a vivid scenario between interim periods from 2003-13 and taken together averaged by 33.35\% (in case of positive transition) and 19.96 (in case of negative transition) also be likely to be found against $25.34 \%$ and $37.35 \%$ respectively during the preceding last ten years. In case of course transition rate tends to be zero between Classes I to II and Class II to III for the academic year of 2004-05 and 2005-06 respectively. Due to internal efficiency of school shall remain unchanged to the zero transitions e.g. repetition, dropout, illiteracy rates, new entrances etc. But, incidence of maximum and minimum transition has to be found in 2007-08 for Class I to Class II transition (60.86\%) and -66.66 found for Class I to II and Class II to III in 2006-07 and 2007-08 academic years respectively. Table 5 shows Transition rate from Class I to Class IV through Class II and Class III for total enrolment for two schools with their academic years. Figure 2 also shows transition rate on or after Class I to Class IV through Class II and Class III for total enrolment for 1) Madansol Primary School and 2) Baital Para Primary School through their academic years.

In case of positive transition rate Madansol Primary School, Class I to Class II, Class II to Class III, and Class III to Class IV fell into the medium transition class (26\% - 50\%) for three sessions (2003-04, 2007-08, 2012-13), three sessions (2003-04, 2004-05, 2008-09) and four sessions (2004-05, 2005-06, 2009-10, 2011-12) respectively and so on for other low transition class. But no classes fell into high and very high transition class. Despite the fact that, Class I to Class II, Class II to Class III, and Class III to Class IV fell into the Low transition class $(0 \%-25 \%)$ for four sessions (2004-05, 2008-09, 2010-11, 2012-13), three sessions (2003- 04, 2005-06, 2009-10, 2011-12) and one session (2004-05) respectively in case of Baital Para Primary School and so on. In this circumstance, no successive class promotion has experienced very high transition Table 6.

In case of negative transition rate Madansol Primary School, Class I to Class II, Class II to Class III, and 
Table 5. Transition rate by male/female enrolment in each class, i.e. Class I to Class IV.

\begin{tabular}{|c|c|c|c|c|c|c|c|c|c|c|c|c|c|c|c|c|c|c|c|}
\hline & \multirow{3}{*}{ Year } & \multirow{2}{*}{\multicolumn{2}{|c|}{$\begin{array}{c}\text { Enrolment in } \\
\text { Class-I }\end{array}$}} & \multirow{2}{*}{\multicolumn{3}{|c|}{$\begin{array}{l}\text { Enrolment in } \\
\text { Class-II }\end{array}$}} & \multirow{2}{*}{\multicolumn{3}{|c|}{$\begin{array}{l}\text { Enrolment in } \\
\text { Class-III }\end{array}$}} & \multirow{2}{*}{\multicolumn{4}{|c|}{ Enrolment in Class-IV }} & \multicolumn{6}{|c|}{ Transition Rate (\%) } \\
\hline & & & & & & & & & & & & & & \multicolumn{2}{|c|}{ Class I to II } & \multicolumn{2}{|c|}{ Class II to III } & \multicolumn{2}{|c|}{ Class III to IV } \\
\hline & & $\mathbf{M}$ & $\mathbf{F}$ & Total & $\mathbf{M}$ & $\mathbf{F}$ & Total & $\mathbf{M}$ & $\mathbf{F}$ & Total & $\mathbf{M}$ & $\mathbf{F}$ & Total & $\mathbf{M}$ & $\mathbf{F}$ & $\mathbf{M}$ & $\mathbf{F}$ & $\mathbf{M}$ & $\mathbf{F}$ \\
\hline \multirow{10}{*}{$\begin{array}{l}\mathrm{M} \\
\mathrm{S} \\
\mathrm{P} \\
\mathrm{S}\end{array}$} & 2003-04 & 12 & 25 & 37 & 10 & 11 & 21 & 6 & 5 & 11 & 9 & 3 & 12 & 16.66 & 56.00 & 40.00 & 54.54 & -50.00 & 40.00 \\
\hline & 2004-05 & 15 & 14 & 29 & 12 & 25 & 37 & 9 & 11 & 20 & 6 & 5 & 11 & 20.00 & -78.57 & 25.00 & 56.00 & 33.33 & 54.54 \\
\hline & 2005-06 & 15 & 19 & 34 & 15 & 14 & 29 & 12 & 24 & 36 & 9 & 11 & 20 & 0.00 & 26.31 & 20.00 & -71.42 & 25.00 & 54.16 \\
\hline & 2006-07 & 9 & 9 & 18 & 15 & 18 & 33 & 15 & 13 & 28 & 11 & 23 & 34 & -66.66 & -100.00 & 0.00 & 27.77 & 26.66 & -76.92 \\
\hline & 2007-08 & 11 & 13 & 24 & 7 & 10 & 17 & 13 & 17 & 30 & 14 & 13 & 27 & 36.36 & 23.07 & -85.71 & -70.00 & -7.69 & 25.32 \\
\hline & 2008-09 & 16 & 14 & 30 & 11 & 12 & 23 & 7 & 9 & 16 & 13 & 17 & 30 & 31.25 & 14.28 & 36.36 & 25.00 & -85.71 & -88.88 \\
\hline & 2009-10 & 20 & 17 & 37 & 16 & 13 & 29 & 11 & 12 & 23 & 7 & 5 & 12 & 20.00 & 23.52 & 31.25 & 7.69 & 36.36 & 5833 \\
\hline & 2010-11 & 11 & 13 & 24 & 19 & 16 & 35 & 15 & 13 & 28 & 11 & 12 & 23 & -72.72 & -23.07 & 21.05 & 18.75 & 26.66 & 7.69 \\
\hline & 2011-12 & 9 & 7 & 16 & 11 & 13 & 24 & 19 & 16 & 35 & 14 & 12 & 26 & -22.22 & -85.71 & -72.72 & -23.07 & 26.31 & 25.00 \\
\hline & $2012-13$ & 17 & 11 & 28 & 9 & 7 & 16 & 11 & 12 & 23 & 18 & 15 & 33 & 47.05 & 36.36 & -22.22 & -71.48 & -63.63 & -25.00 \\
\hline \multirow{10}{*}{$\begin{array}{l}\mathrm{B} \\
\mathrm{P} \\
\mathrm{S}\end{array}$} & 2003-04 & 5 & 5 & 10 & 7 & 9 & 16 & 5 & 8 & 13 & 10 & 6 & 16 & -40.00 & -80.00 & 28.57 & 11.11 & -100.00 & 25.00 \\
\hline & 2004-05 & 8 & 4 & 12 & 5 & 7 & 12 & 7 & 8 & 15 & 5 & 8 & 13 & 37.50 & -75.00 & -40.00 & -14.28 & 28.57 & 0.00 \\
\hline & 2005-06 & 7 & 8 & 15 & 8 & 3 & 11 & 5 & 6 & 11 & 7 & 8 & 15 & -14.28 & 62.5 & 37.50 & -100.00 & -40.00 & -33.33 \\
\hline & 2006-07 & 5 & 4 & 9 & 7 & 8 & 15 & 9 & 2 & 11 & 4 & 2 & 6 & -40.00 & -100.00 & -28.57 & 75.00 & 55.55 & 0.00 \\
\hline & 2007-08 & 9 & 14 & 23 & 5 & 4 & 9 & 7 & 8 & 15 & 9 & 2 & 11 & 44.44 & 71.42 & -40.00 & -100.00 & -28.57 & 75.00 \\
\hline & 2008-09 & 13 & 9 & 22 & 8 & 13 & 21 & 5 & 4 & 9 & 7 & 7 & 14 & 38.46 & -77.77 & 37.50 & 69.23 & -28.57 & -75.00 \\
\hline & 2009-10 & 7 & 8 & 15 & 13 & 9 & 22 & 8 & 12 & 20 & 6 & 3 & 9 & -85.71 & -12.5 & 38.46 & -33.33 & 25.00 & 75.00 \\
\hline & 2010-11 & 11 & 9 & 20 & 6 & 9 & 15 & 10 & 8 & 18 & 8 & 12 & 20 & 45.45 & 0.00 & -66.66 & 11.11 & 20.00 & -50.00 \\
\hline & 2011-12 & 10 & 8 & 18 & 10 & 9 & 19 & 6 & 9 & 15 & 10 & 8 & 18 & 0.00 & -12.5 & 40.00 & 0.00 & -66.66 & 11.11 \\
\hline & 2012-13 & 7 & 12 & 19 & 9 & 8 & 17 & 10 & 9 & 19 & 6 & 8 & 14 & -28.57 & 33.33 & -11.11 & -12.5 & 40.00 & 11.11 \\
\hline
\end{tabular}

$\mathrm{N}: \mathrm{B}$ M Stands male and F stands female.

Class III to Class IV fell into the very high transition class ( $-76 \%$ to $-100 \%)$ for one session (2006-07), one session (2007-08) and one session (2008-09) respectively and so on for other remaining transition classes. But no classes fell into high transition class. While, Class I to Class II, Class II to Class III, and Class III to Class IV fell into the low transition class (<-25\%) for one session (2011-12), three sessions (2004-05, 2010-11, 2012-13) and three sessions (2003-04, 2010-11, 2011-12) respectively in case of Baital Para Primary School and so on. In this circumstance, no successive class promotion has experienced very high transition.

In this way paper analyses the male and female transition rate by successive classes for both schools. Significant difference in transition rate is noticed in case of males and females for distinct two schools by averaged together taken into account for all classes and all academic sessions. Separately, transition rate in case of males and females both shows improvement in 2008-09 and 2003-04 respectively over the considered academic years in all classes at Madansol Primary School but in overall regime no significant difference in transition rate is found in case of males and females. Moreover, Baital Para Primary School experienced high transition improvement in males (56.67\%) than female (43.33\%).

In case of male positive transition rate in Madansol Primary School, Class I to Class II, Class II to Class III, and Class III to Class IV fell into the medium transition class (26\% - 50\%) for three sessions (2007-08, 2008-09, 2012-13), three sessions (2003-04, 2008-09, 2009-10) and four sessions (2004-05, 2006-07, 2009-10, 2010-11, 2011-12) respectively and so on for other low transition class. But no classes fell into very high transition class. Despite the fact that, Class I to Class II, Class II to Class III, and Class III to Class IV fell into the medium transition class (26\% - 50\%) for two sessions (2005-06, 2012-13), one session (2006-07) and one session $(2003-04,2007-08)$ respectively in case of female positive transition rate in Madansol Primary 
Table 6. Transition rate from Class I to Class IV through Class II and Class III for male and female enrolment for two schools with their academic years.

\begin{tabular}{|c|c|c|c|c|c|c|c|c|}
\hline \multirow{2}{*}{ School } & \multirow{2}{*}{$\begin{array}{c}\text { Positive } \\
\text { value }(+)\end{array}$} & \multirow{2}{*}{ Transition } & \multicolumn{2}{|c|}{ Class I to II } & \multicolumn{2}{|c|}{ Class II to III } & \multicolumn{2}{|c|}{ Class III to IV } \\
\hline & & & $\mathbf{M}$ & $\mathbf{F}$ & $\mathbf{M}$ & $\mathbf{F}$ & $\mathbf{M}$ & $\mathbf{F}$ \\
\hline \multirow{4}{*}{ MSPS } & $76-100$ & Very high & Nil & Nil & Nil & Nil & Nil & Nil \\
\hline & $51-75$ & High & Nil & 2003-04 & Nil & $\begin{array}{l}\text { 2003-04, } \\
2004-05\end{array}$ & $\mathrm{Nil}$ & $\begin{array}{c}2004-05 \\
2005-06 \\
2009-10\end{array}$ \\
\hline & $26-50$ & Medium & $\begin{array}{c}\text { 2007-08, 2008-09, } \\
2012-13\end{array}$ & 2005-06, 2012-13 & $\begin{array}{c}2003-04 \\
2008-09 \\
2009-10\end{array}$ & 2006-07 & $\begin{array}{l}2004-05 \\
2006-07 \\
2009-10 \\
2010-11 \\
2011-12\end{array}$ & $\begin{array}{l}\text { 2003-04, } \\
2007-08\end{array}$ \\
\hline & $0-25$ & Low & $\begin{array}{c}\text { 2003-04, 2004-05, } \\
2005-06,2009-10\end{array}$ & $\begin{array}{c}\text { 2007-08, 2008-09, } \\
2009-10\end{array}$ & $\begin{array}{l}2004-05 \\
2005-06 \\
2006-07 \\
2010-11\end{array}$ & $\begin{array}{l}2008-09 \\
2009-10 \\
2010-11\end{array}$ & Nil & 2011-12 \\
\hline \multirow{4}{*}{ BPS } & $76-100$ & Very high & Nil & Nil & Nil & 2006-07 & $\mathrm{Nil}$ & $2009-10$ \\
\hline & $51-75$ & High & Nil & 2005-06, 2007-08 & Nil & 2008-09 & 2006-07 & $\begin{array}{l}2007-08 \\
2009-10\end{array}$ \\
\hline & $26-50$ & Medium & $\begin{array}{c}2004-05,2007-08 \\
2008-09,2010-11\end{array}$ & 2012-13 & $\begin{array}{c}2003-04 \\
2005-06 \\
2008-09 \\
2009-10\end{array}$ & $\mathrm{Nil}$ & $\begin{array}{l}\text { 2004-05, } \\
2012-13\end{array}$ & Nil \\
\hline & $0-25$ & Low & 2011-12 & Nil & Nil & $\begin{array}{l}2003-04 \\
2010-11\end{array}$ & 2009-10 & $\begin{array}{c}2003-04 \\
2011-12 \\
2012-13\end{array}$ \\
\hline \multirow{2}{*}{ School } & \multirow{2}{*}{$\begin{array}{l}\text { Negative } \\
\text { value }(+)\end{array}$} & \multirow{2}{*}{ Transition } & \multicolumn{2}{|c|}{ Class I to II } & \multicolumn{2}{|c|}{ Class II to III } & \multicolumn{2}{|c|}{ Class III to IV } \\
\hline & & & $\mathbf{M}$ & $\mathbf{F}$ & $\mathbf{M}$ & $\mathbf{F}$ & $\mathbf{M}$ & $\mathbf{F}$ \\
\hline \multirow{4}{*}{ MSPS } & -76 to -100 & Very high & $\mathrm{Nil}$ & $\begin{array}{c}\text { 2004-05, 2006-07, } \\
2011-12\end{array}$ & 2007-08 & $\mathrm{Nil}$ & 2008-09 & $\begin{array}{l}\text { 2006-07, } \\
2008-09\end{array}$ \\
\hline & -51 to -75 & High & 2006-07, 2010-11 & Nil & 2011-12 & $\begin{array}{l}2005-06 \\
2007-08 \\
2012-13\end{array}$ & $\begin{array}{l}\text { 2003-04, } \\
2012-13\end{array}$ & Nil \\
\hline & -26 to -50 & Medium & Nil & Nil & Nil & Nil & Nil & Nil \\
\hline & $<-25$ & Low & 2011-12 & 2010-11 & 2012-13 & 2012-13 & 2007-08 & $2012-13$ \\
\hline \multirow{4}{*}{ BPS } & -76 to -100 & Very high & $2009-10$ & $\begin{array}{c}\text { 2003-04, 2006-07, } \\
\text { 2008-09 }\end{array}$ & Nil & $\begin{array}{l}\text { 2005-06, } \\
2007-08\end{array}$ & 2003-04 & \\
\hline & -51 to -75 & High & Nil & 2004-05 & 2010-11 & Nil & 2011-12 & 2008-2009 \\
\hline & -26 to -50 & Medium & $\begin{array}{c}\text { 2003-04, 2006-07, } \\
\text { 2012-13 }\end{array}$ & Nil & $\begin{array}{c}2004-05 \\
2006-07 \\
2007-08\end{array}$ & 2009-10 & $\begin{array}{c}2005-06 \\
2007-08 \\
2008-09\end{array}$ & $\begin{array}{l}2010-11 \\
2005-06\end{array}$ \\
\hline & $<-25$ & Low & Nil & 2009-10, 2011-12 & 2012-13 & $\begin{array}{l}\text { 2004-05, } \\
2011-12 \\
2012-13\end{array}$ & Nil & $\begin{array}{l}2004-05 \\
2006-07\end{array}$ \\
\hline
\end{tabular}

N:B M Stands male and F stands female.

School and so on. In this circumstance, no successive class promotion has experienced very high transition for both male and female.

In case of male positive transition rate in Baital Para Primary School, Class I to Class II, Class II to Class III, and Class III to Class IV fell into the medium transition Class (26\% - 50\%) for four sessions (2004-05, 2007-08, 2008-09, 2010-11), three sessions (2003-04, 2005-06, 2008-09, 2009-10) and two sessions (2004-05, 2012-13) respectively and so on for other low transition class. But no classes fell into very high transition class in case male. In spite of the fact that, only Class I to Class II, fell into the medium transition class (26\% - 

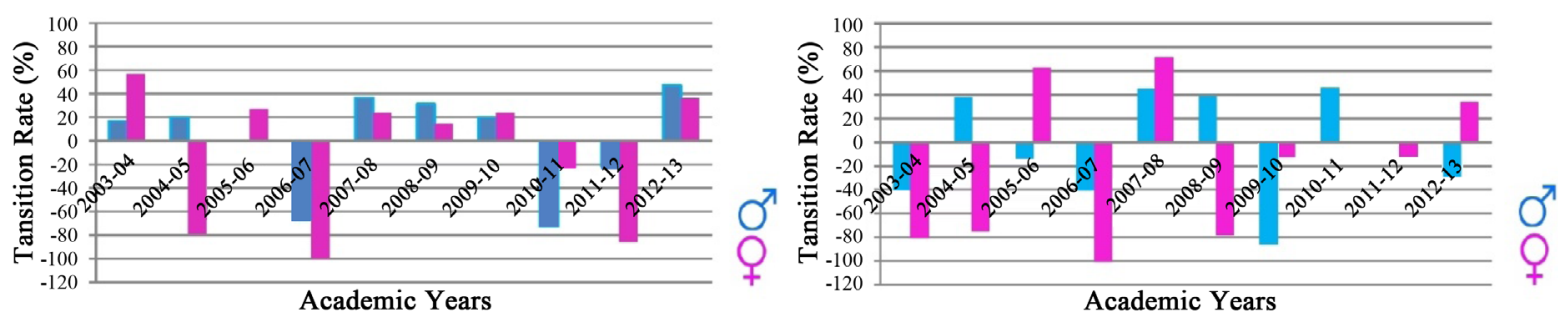

(a)
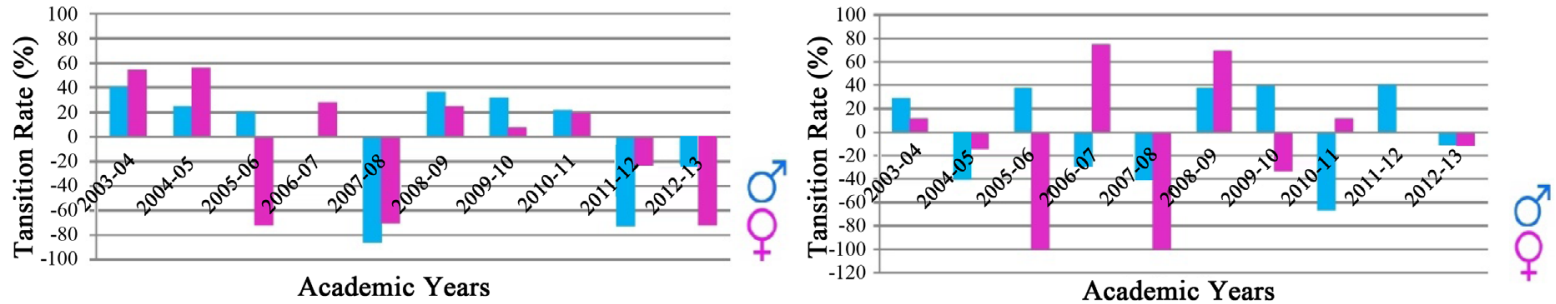

(b)
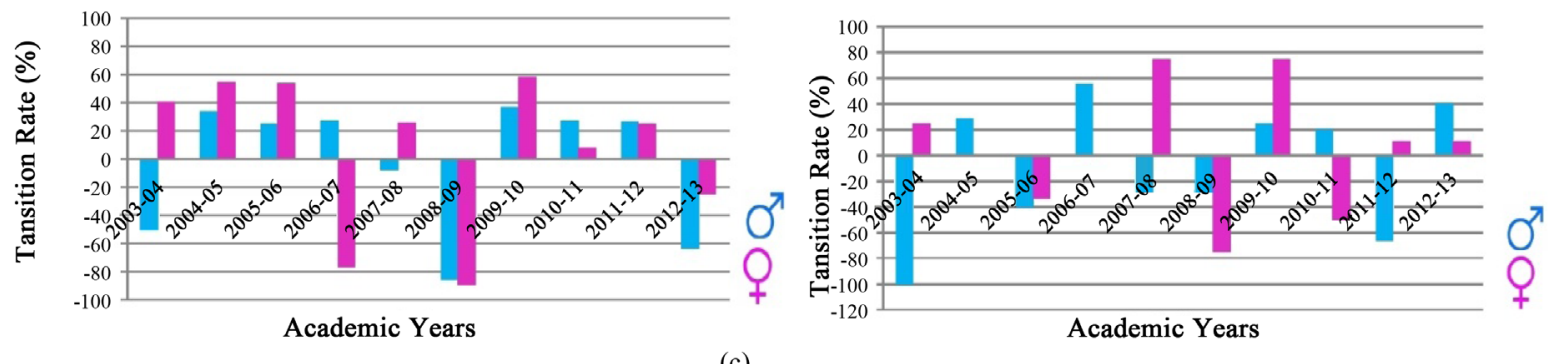

(c)

Figure 2. The transition rate from Class I to Class IV through Class II and Class III for male/female for (left) Madansol Primary School viz. (a) Class I to II, (b) Class II to III and (c) Class III to IV and (right) Baital Para Primary school viz. (a) Class I to II, (b) Class II to III and (c) Class III to IV with their academic years.

50\%) for one session (2012-13), respectively in case of female positive transition rate in Baital Para Primary School and so on. In this circumstance, no successive class promotion has experienced very high transition for male but female Class II to III and Class III to Class IV have attained those in the academic years of 2006-07 and 2009-10 respectively. In the study all academic classes have attained normally in medium transition rate.

In case of male negative transition rate brought in Madansol Primary School, Class I to Class II, Class II to Class III, and Class III to Class IV fell into the medium transition class ( $-26 \%$ to $-50 \%$ ) for entire period is negligible respectively and so on for other low transition class and only each single academic years posses the same. Despite the fact that, Class I to Class II, Class II to Class III, and Class III to Class IV fell into the negative medium transition class (-26\% to $-50 \%$ ) for three sessions (2003-04, 2006-07, 2012-13), three sessions (2004-05, 2006-07, 2007-08) and three session (2005-06, 2007-08, 2008-09) respectively in case of male negative transition rate in Madansol Primary School and so on. In this circumstance, rest successive class promotion has experienced very high transition to low.

In case of male negative transition rate brought in Baital Para Primary School, Class I to Class II, Class II to Class III, and Class III to Class IV fell into the medium transition class ( $-26 \%$ to $-50 \%)$ for entire period is negligible respectively and so on for other low transition class and only each single academic years posses the same. Despite the fact that, Class I to Class II, Class II to Class III, and Class III to Class IV fell into the negative medium transition class (-26\% to $-50 \%$ ) for three sessions (2003-04, 2006-07, 2012-13), three sessions (2004-05, 2006-07, 2007-08) and three sessions (2005-06, 2007-08, 2008-09) respectively in case of male negative transition rate in Madansol Primary School and so on. In this circumstance, rest successive class promotion has experienced very high transition to low.

In case of female negative transition rate brought in Madansol Primary School, Class I to Class II, Class II to Class III, and Class III to Class IV fell into the medium transition class ( $-26 \%$ to $-50 \%)$ for entire period is neg- 
ligible respectively and so on for other low transition class and only each single academic years posses the same. Despite the fact that, Class I to Class II, Class II to Class III, and Class III to Class IV fell into the negative low transition Class (<-25\%) for one session (2010-11), one session (2012-13) and one session (2012-13) respectively in case of female negative transition rate in Madansol Primary School and so on. In this circumstance, rest successive class promotion has experienced very high transition to low.

In case of female negative transition rate brought in Baital Para Primary School, Class I to Class II, Class II to Class III, and Class III to Class IV fell into the medium transition class ( $-26 \%$ to $-50 \%$ ) for entire period is negligible respectively and so on for other low transition class and only each single academic years posses the same. Despite the fact that, Class II to Class III, and Class III to Class IV fell into the negative medium transition class $(-26 \%$ to $-50 \%)$ for one session (2009-10), and two sessions (2010-11, 2005-06) respectively in case of female negative transition rate in Baital Para Primary School and so on. In this circumstance, rest successive class promotion has experienced very high transition to low.

Against 69.96\% males, about 65.36\% females transited from Class I to Class II level of education in 2004 against 66.01\% males and 61.98\% females during the previous year, i.e. 2003. Though transition rate from Class I to Class II level shows improvement but still about 22\% children drop-out in transition which may play significant role towards moving goal of universalization of elementary education.

Further, a significant deviation is noticed when school-specific transition rates are analyzed which is presented in Table 6. As against a low transition rate of 57.62\% in Baital Para Primary School, the same is very high in case of a few classes of Madansol Primary School. As it seems that the goal of universal elementary education in these schools may not be realized in the near future if transition rates are not improved significantly. By conducting studies, the schools should know reasons of low transition, which should be followed by incorporation of reason-specific strategies in the Annual Work Plan and Budget. Over all scenario has been put on transition rate from Class I to Class IV through Class II and Class III for male/female for (left) Madansol Primary school viz. 1) Classes I to II, 2) Classes II to III and 3) Classes III to IV and (right) Baital Para Primary School viz. (a) Classes I to II, (b) Classes II to III and (c) Classes III to IV with their academic years in Figure 2.

\subsection{Gender Parity Index (GPI)}

Despite the critical progress in bridging gender gaps, persistent inequalities remain in many regions and at different Primary levels of education. Table 7 and Figure 3 highlight the varying rate in gender parity at different primary education levels at two schools. The gender parity index shows that only Madansol Primary School and the Baital Para School has reached or is close to gender parity in all levels of primary education. Almost Baital Para School are closer to gender parity at the primary level than at any other level of education, except for the Madansol Primary School where primary education is closest to a position of parity. The majority of countries fell short of achieving the first step towards the gender goal. Similarly, gender parity for each school was derived from male and female registered pupils. The ratio of female and male was used to calculate the gender parity for the schools, which was then multiplied by the percent of value occurrences to obtain the gender parity index (GPI). Gender parity divided into three assigned attributes 1) gender parity index (=1) for parity between females and males pupils; 2) gender parity index $(<1)$ disparity in favour of male pupils; and 3) gender parity index $(>1)$ disparity in favour of female pupils. However, the interpretation should be the other way round for indicators that should ideally approach $0 \%$ (e.g. repetition, dropout, illiteracy rates, etc. In case Madansol primary school gender disparity tends to have slight disparity in favour of female pupils for the periods from 20032013 viz. Class I, Class II, Class III and Class IV with values of gender disparity 1.07, 1.14, 1.14 and 1.02 respectively in Table 7.

But only parity exists in 2006-07 session at class level. On the other hand, In case Baital Para School gender disparity tends to have also slight disparity in favour of female pupils for the periods from 2003-2013 viz. Class I, Class II, and Class III with values of gender disparity 1.01, 1.01, and 1.08 respectively. While, Class IV having gender parity score 0.95, reveals disparity in favour of male pupils. But parity exists in session of 2003-04 and 2008-09 at Class I and Class II level with 2.5\% for both classes respectively in Table 8. Moreover, 12\% $14 \%$ out of total considered period comprises gender parity value ranges between $<1$ to $>1$. Hence the disparity in favour of male or female has to be changed in high at Madansol Primary School then Baital Para Primary School. Figure 3 showing the gender parity index (GPI) and their class wise assigned attributes with 
Table 7. Gender parity index (GPI) as socioeconomic index usually designed to measure the relative access to education of males and females in two schools.

\begin{tabular}{|c|c|c|c|c|c|c|c|c|c|c|c|c|c|}
\hline & \multirow{2}{*}{ Years } & \multicolumn{3}{|c|}{ Enrolment in Class I } & \multicolumn{3}{|c|}{ Enrolment in Class II } & \multicolumn{3}{|c|}{ Enrolment in Class III } & \multicolumn{3}{|c|}{ Enrolment in Class IV } \\
\hline & & $\mathbf{M}$ & $\mathbf{F}$ & GPI & $\mathbf{M}$ & $\mathbf{F}$ & GPI & $\mathbf{M}$ & $\mathbf{F}$ & GPI & $\mathbf{M}$ & $\mathbf{F}$ & GPI \\
\hline \multirow{10}{*}{$\begin{array}{l}\mathrm{M} \\
\mathrm{S} \\
\mathrm{P} \\
\mathrm{S}\end{array}$} & 2003-04 & 12 & 25 & 2.08 & 10 & 11 & 1.10 & 6 & 5 & 0.83 & 9 & 3 & 0.33 \\
\hline & 2004-05 & 15 & 14 & 0.93 & 12 & 25 & 2.08 & 9 & 11 & 1.22 & 6 & 5 & 0.83 \\
\hline & 2005-06 & 15 & 19 & 1.26 & 15 & 14 & 0.93 & 12 & 24 & 2.00 & 9 & 11 & 1.22 \\
\hline & 2006-07 & 9 & 9 & 1.00 & 15 & 18 & 1.20 & 15 & 13 & 0.86 & 11 & 23 & 2.09 \\
\hline & 2007-08 & 11 & 13 & 1.18 & 7 & 10 & 1.42 & 13 & 17 & 1.30 & 14 & 13 & 0.92 \\
\hline & 2008-09 & 16 & 14 & 0.87 & 11 & 12 & 1.09 & 7 & 9 & 1.28 & 13 & 17 & 1.30 \\
\hline & 2009-10 & 20 & 17 & 0.85 & 16 & 13 & 0.81 & 11 & 12 & 1.09 & 7 & 5 & 0.71 \\
\hline & 2010-11 & 11 & 13 & 1.18 & 19 & 16 & 0.84 & 15 & 13 & 0.86 & 11 & 12 & 1.09 \\
\hline & 2011-12 & 9 & 7 & 0.77 & 11 & 13 & 1.18 & 19 & 16 & 0.84 & 14 & 12 & 0.85 \\
\hline & 2012-13 & 17 & 11 & 0.64 & 9 & 7 & 0.77 & 11 & 12 & 1.09 & 18 & 15 & 0.83 \\
\hline \multirow{10}{*}{$\begin{array}{l}\text { B } \\
\text { P } \\
\text { S }\end{array}$} & 2003-04 & 5 & 5 & 1.00 & 7 & 9 & 1.28 & 5 & 8 & 1.60 & 10 & 6 & 0.86 \\
\hline & 2004-05 & 8 & 4 & 0.50 & 5 & 7 & 1.40 & 7 & 8 & 1.14 & 5 & 8 & 1.60 \\
\hline & 2005-06 & 7 & 8 & 1.14 & 8 & 3 & 0.37 & 5 & 6 & 1.20 & 7 & 8 & 1.14 \\
\hline & 2006-07 & 5 & 4 & 0.80 & 7 & 8 & 1.14 & 9 & 2 & 0.22 & 4 & 2 & 0.50 \\
\hline & 2007-08 & 9 & 14 & 1.55 & 5 & 4 & 0.80 & 7 & 8 & 1.14 & 9 & 2 & 0.22 \\
\hline & 2008-09 & 13 & 9 & 0.69 & 8 & 13 & 1.62 & 5 & 4 & 0.80 & 7 & 7 & 1.00 \\
\hline & 2009-10 & 7 & 8 & 1.14 & 13 & 9 & 0.69 & 8 & 12 & 1.50 & 6 & 3 & 0.50 \\
\hline & 2010-11 & 11 & 9 & 0.81 & 6 & 9 & 1.50 & 10 & 8 & 0.80 & 8 & 12 & 1.50 \\
\hline & 2011-12 & 10 & 8 & 0.80 & 10 & 9 & 0.90 & 6 & 9 & 1.50 & 10 & 8 & 0.80 \\
\hline & 2012-13 & 7 & 12 & 1.71 & 9 & 8 & 0.88 & 10 & 9 & 0.90 & 6 & 8 & 1.33 \\
\hline
\end{tabular}

N:B M Stands male and F stands female.

Table 8. Gender parity index (GPI) and their class wise assigned attributes with different academic years.

\begin{tabular}{|c|c|c|c|c|c|}
\hline School & Index & Class I & Class II & Class III & Class IV \\
\hline \multirow{3}{*}{$\begin{array}{c}\mathrm{M} \\
\mathrm{S} \\
\mathrm{P} \\
\mathrm{S}\end{array}$} & $\mathrm{GPI}=1$ & 2006-07 & Nil & Nil & Nil \\
\hline & GPI $>1$ & $\begin{array}{l}\text { 2003-04, 2005-06, } \\
\text { 2007-08, 2010-11, }\end{array}$ & $\begin{array}{l}2003-04,2004-05 \\
2006-07,2007-08, \\
2008-09,2011-12\end{array}$ & $\begin{array}{l}2004-05,2005-06 \\
2007-08,2008-09 \\
2009-10,2012-13\end{array}$ & $\begin{array}{l}\text { 2005-06, 2006-07, } \\
\text { 2008-09, 2010-11 }\end{array}$ \\
\hline & $\mathrm{GPI}<1$ & $\begin{array}{c}2004-05,2008-09 \\
2009-10,2011-12 \\
2012-13\end{array}$ & $\begin{array}{l}\text { 2005-06, 2009-10, } \\
2010-11,2012-13\end{array}$ & $\begin{array}{l}\text { 2003-04, 2006-07, } \\
2010-11,2011-12\end{array}$ & $\begin{array}{l}\text { 2003-04, 2004-05, } \\
2007-08,2009-10, \\
2011-12,2012-13\end{array}$ \\
\hline \multirow{3}{*}{$\begin{array}{l}\mathrm{B} \\
\mathrm{P} \\
\mathrm{S}\end{array}$} & $\mathrm{GPI}=1$ & 2003-04 & Nil & Nil & 2008-09 \\
\hline & $\mathrm{GPI}>1$ & $\begin{array}{l}\text { 2005-06, 2007-08, } \\
\text { 2009-10, 2012-13 }\end{array}$ & $\begin{array}{c}\text { 2003-04, 2004-05, } \\
\text { 2006-07, 2008-09, 2010-11 }\end{array}$ & $\begin{array}{l}2003-04,2004-05 \\
2005-06,2007-08 \\
2009-10,2011-12\end{array}$ & $\begin{array}{l}\text { 2004-05, 2005-06, } \\
2010-11,2012-13\end{array}$ \\
\hline & $\mathrm{GPI}<1$ & $\begin{array}{c}2004-05,2006-07 \\
2008-09,2010-11 \\
2011-12\end{array}$ & $\begin{array}{c}\text { 2005-06, 2007-08, } \\
\text { 2009-10, 2011-12, 2012-13 }\end{array}$ & $\begin{array}{l}2006-07,2008-09 \\
2010-11,2012-13\end{array}$ & $\begin{array}{c}\text { 2003-04, 2006-07, } \\
\text { 2007-08, 2009-10, 2011-12 }\end{array}$ \\
\hline
\end{tabular}




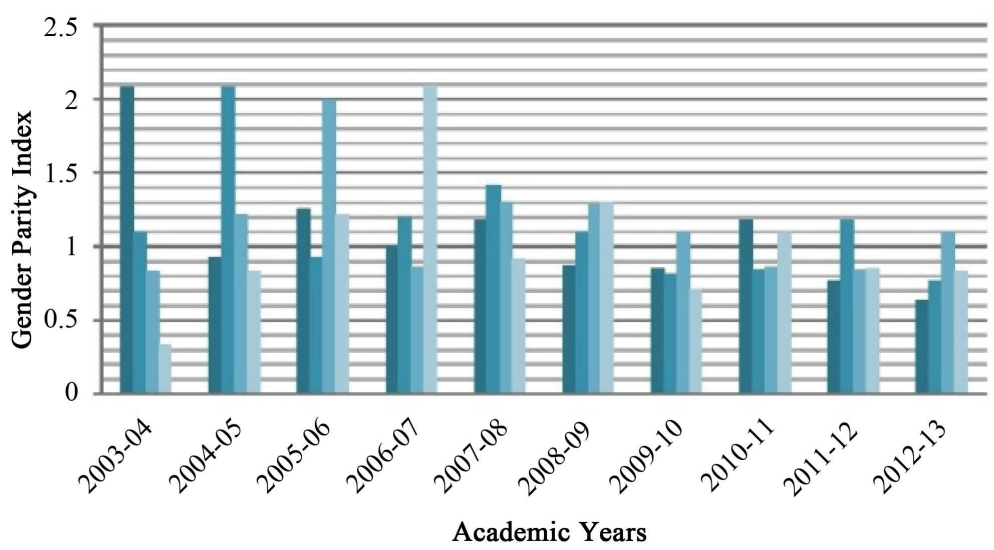

nClass-I

m Class-II

- Class-III

- Class-IV

(a)

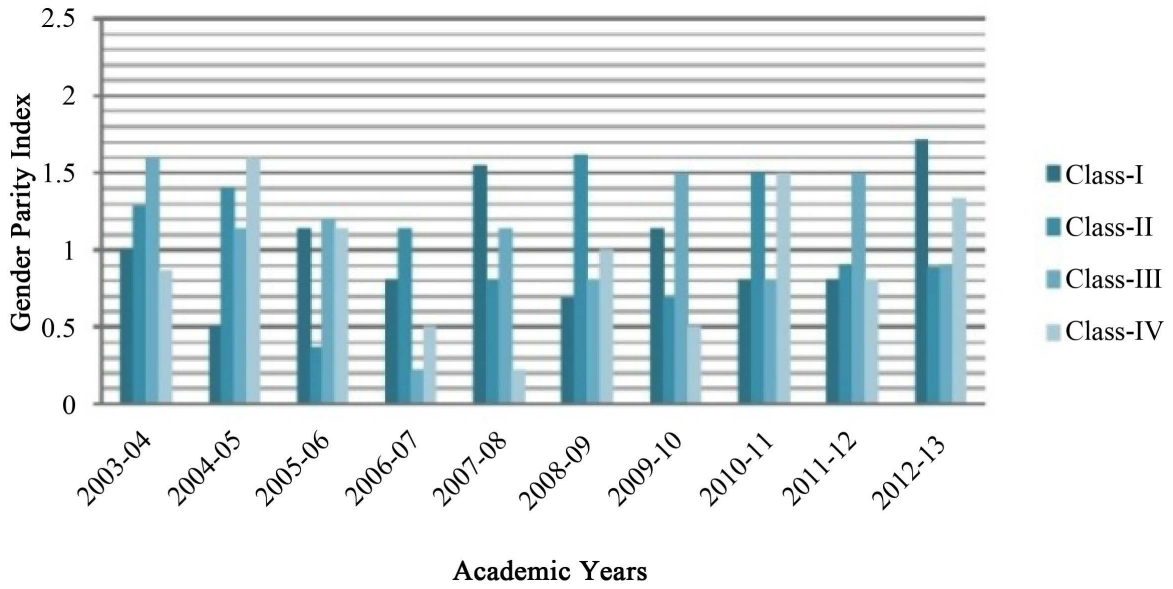

(b)

Figure 3. Gender parity index (GPI) and their class wise assigned attributes with different academic years for (a) Madansol Primary School and (b) Baital Para Primary School with their academic years.

different academic years for 1) Madansol Primary School and 2) Baital Para Primary School with their respective academic years.

\section{Conclusion}

In summary, more is known than ever before about the forces that help students stay on track or lead them to transition rate of school. There is a great deal that states, school districts, and schools can do to bolster the holding power of primary schools. There is much more that can be done, starting with clarifying what transition rate and gender parity is and how the Transition rate and gender parity phenomenon is best measured so that early warning and accountability systems can be put into place. Transition rate and gender parity prevention strategies need to address both school-level and community-level issues. Effective efforts will reflect not only risk factors, but also the factors that foster resiliency and help students stay on track despite difficulties.

Transition rate at the primary stage was $87.5 \%$ for the year $2008-09$ and it decreased marginally to $87.2 \%$ in 2009-10. West Bengal recorded the lowest transition rate (80.9\%) in 2008-09. The study had the following recommendations that are greater budgetary allocation should be made to the education sector and it should place a greater emphasis on the financing of rural primary school education to cater not only for the tuition but other allied accompanying costs like boarding fees. This will greatly bring down the costs and help make the rural primary school education more affordable and have a wider access to it by the many citizens missing out owing to the element of the costs involved. More focus should be placed on the rural economies in the quest to improve them. This can be by way of having industrialization programmes and activities meant to spur eco- 
nomic growth and bridge the inequalities between the rural and urban spheres. This will greatly impact on the levels of exposures the populace's disposable incomes and greatly impact on the capacity to pay for education programmes in rural primary school and at higher levels. Parents should be sensitized on the need to have their children progressing and attaining high levels and standards of education. This should be done by way of involvement of community levels and opinion leaders from all spheres so as to shape the community's thinking and have a change of attitudes to attaching a higher value and premium to education. Communities should always seek to take change and intervene in situations threatening the livelihood and futures of young learners. Several aspects were noticed in the study which should be adopted by the head teachers, teachers, community, parents, stakeholders and the government in order to reduce transition rate and gender parity among female students from secondary schools. The following recommendations were made:

- The government through the West Bengal Board of Primary Education (WBBPE) should continue to develop and implement policies to ensure that female who drop out of primary school due to uncontrolled enroll back to school. The schools should create an enabling environment for female to enhance retention and smooth transition.

- The school management should enhance guidance and counselling in schools so as to address the challenges facing the female students like relationships, peer influence, drugs and substance abuse. This will enhance retention of the female students.

- The WBBPE should provide capacity building for head teachers and teachers in areas like guidance and counselling and efficiency management of schools particularly studied schools.

- The WBBPE should ensure that schools set realistic and achievable academic pass marks for students. This will address the issue of forced repetition and hence enhance smooth transition.

\section{Acknowledgements}

We would like to express our gratitude to the students of both schools for providing us valuable information on various socio-economic aspects of dropout. For this work we would also indebt to the Head Master of both primary schools for helping in collecting quantative and qualitative data. We would express our gratitude to all whose names have not been mentioned individually but have helped us in this work.

\section{References}

Aikara, J. (1997). Learner Achievement in Primary Schools. Mumbai: Tata Institute of Social Sciences, Unit for Research in the Sociology of Education.

Alspaugh, J. W. (1998b). The Relationship of School-to-School Transitions and School Size to High School Dropout Rates. The High School Journal, 82, 154-160.

Alspaugh, J. W. (1998c). The Relationship of School and Community Characteristics to High School Drop-Out Rates. The Clearing House, 72, 184-188. http://dx.doi.org/10.1080/00098659809599356

Alspaugh, J. W., \& Harting, R. D. (1995). Transition Effects of School Grade-Level Organization on Student Achievement. Journal of Research and Development in Education, 28, 145-149.

Alspaugh, J. W. (1998a). Achievement Loss Associated with the Transition to Middle School and High School. Journal of Educational Research, 92, 20-25. http://dx.doi.org/10.1080/00220679809597572

Alspaugh, J. W. (1998d). The Relationship of School-to-School Transitions and School Size to High School Dropout Rates. High School Journal, 81, 154

Anderson, L., Jacobs, J., Schramm, J., \& Splittberg, F. (2000). School Transitions: Beginnings of the End or New Beginning? International Journal of Educational Research, 33, 325-339. http://dx.doi.org/10.1016/S0883-0355(00)00020-3

Bajpai, N. (2003). Towards the Millennium Development Goals Occasional Paper. India: UNDP.

Blyth, D. A., Simmons, R. G., \& Carlton-Ford, S. (1983). The Adjustment of Early Adolescents to School Transition. Journal of Early Adolescence, 2, 105-120. http://dx.doi.org/10.1177/027243168331008

Breen, R., \& Buchman, M. (2002). Institutional Variations and the Position of Young People: A Comparative Perspective. Annals of American Academy of Political and Social Science, 580, 288-305.

http://dx.doi.org/10.1177/0002716202580001012

Bruner, J. (1996). The Culture of Education. Boston, MA: Harvard University Press.

Bryk, A. S., \& Thum, Y. M. (1989). The Effects of High School Organization on Dropping out: An Exploratory Investigation. American Educational Research Journal, 26, 353-383. http://dx.doi.org/10.3102/00028312026003353 
Campbell, H. (2001). Easing the Transition to High School. The Education Digest, 67, 12-18.

Clayton, P. (2006). Literacy in Kerala. Report, Glasgow: Development of Adult and Continuing Education, University of Glasgow.

Dev, A. (1995). Secondary Education in India: A Status Paper. In Council of Boards of School Education in India (Ed.), Towards Quality Secondary Education: An Agenda for 21st Century. New Delhi: Vikas.

Dreze, J., \& Sen, A. (2002). India Development and Participation. Oxford: Oxford University Press.

Dubois, D., Eitel, S., \& Felner, D. (1994). Effects of Family Environment and Parent-Child Relationships on School Adjustment during the Transition to Early Adolescence. Journal of Marriage and Family, 56, 405-414. http://dx.doi.org/10.2307/353108

Frymier, J. (1996). Determining Dropout Rates in Large City School Districts: Problems and Accomplishments. The High School Journal, 80, 1-10.

Gardner, P. W., Ritblatt, S. N., \& Beatty, J. R. (2000). Academic Achievement and Parental School Involvement as a Function of High School Size. The High School Journal, 83, 21-27.

Jain, V. K., \& Arora, A. P. (1995). Effect of School Level Variables on Achievement Gap between Boys and Girls. Indian Educational Review, 30.

Kaplan, D. S., Damphousse, K. R., \& Kaplan, H. B. (1996). Moderating Effects of Gender on the Relationship between Not Graduating from High School and Psychological Dysfunction in Young Adults. Journal of American Psychology, 88, 760-774.

Lee, V. E., \& Smith, J. B. (1997). High School Size: Which Works Best and for Whom? Educational Evaluation and Policy Analysis, 19, 205-227. http://dx.doi.org/10.3102/01623737019003205

Lathika, M., \& Ajith Kumar, C. E. (2008). An Analysis of Efficiency of Education in Kerala. Journal of Educational Planning and Administration, 22, 295-310.

Ministry of Human Resource Development (1992). National Policy on Education, 1986 as Modified in 1992 with Programme of Action. New Delhi: Government of India. http://www.education.nic.in/policy/npe86-mod92.pdf

Phelan, W. T. (1992). Building Bonds to High School Graduation: Dropout Intervention with Seventh and Eighth Graders. Middle School Journal, 24, 33-35.

Ramachandran, V. (Ed.) (2004a). Gender and Social Equity in Primary Education: Hierarchies of Access. New Delhi: Sage Publications.

Rumberger, R. W. (1987). High School Dropouts: A Review of Issues and Evidence. Review of Educational Research, 57, 101-121. http://dx.doi.org/10.3102/00346543057002101

Subrahmanian, R. (2003b). Community at the Centre of Universal Primary Education Strategies: An Empirical Investigation. In N. Kabeer, G. Nambissan, \& R. Subrahmanian (Eds.), Child Labour and the Right to Education in South Asia: Needs versus Rights (pp. 216-242). New Delhi: Sage Publications.

Vaidyanathan, A., \& Gopinathan Nair, P. R. (2001). Introduction. In A. Vaidyanathan, \& P. R. Gopinathan Nair (Eds.), Elementary Education in Rural India: A Grassroots View (pp. 23-48). New Delhi: Sage Publications.

World Bank (2003). Equity in Enrolment and Completion in Elementary Schooling in India. New Delhi: World Bank. 
Scientific Research Publishing (SCIRP) is one of the largest Open Access journal publishers. It is currently publishing more than 200 open access, online, peer-reviewed journals covering a wide range of academic disciplines. SCIRP serves the worldwide academic communities and contributes to the progress and application of science with its publication.

Other selected journals from SCIRP are listed as below. Submit your manuscript to us via either submit@scirp.org or Online Submission Portal.
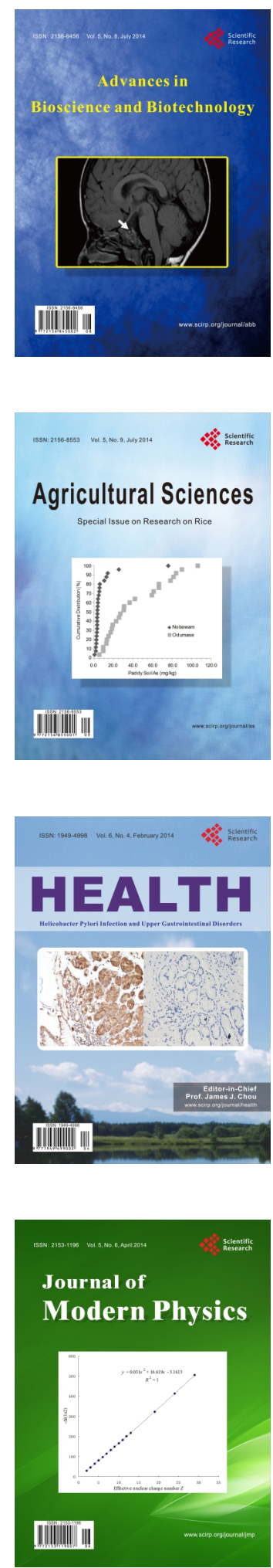
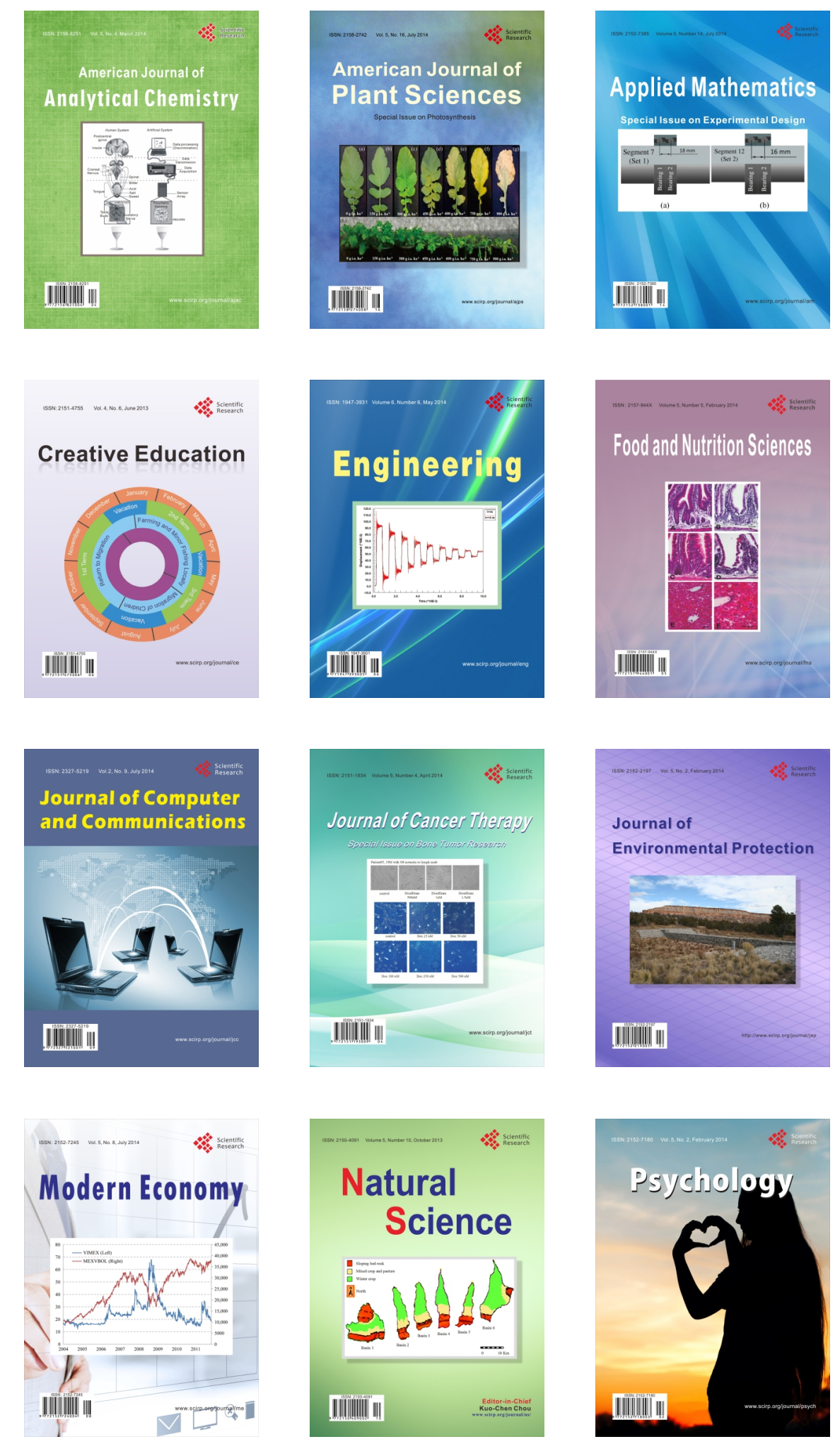